Kampus 4 Universitas Ahmad Dahlan Jl. Ringroad Selatan, Tamanan, Banguntapan, Bantul

Daerah Istimewa Yogyakarta 55191

Telp. : (0274) 563515 Fax. : (0274) 564604

e-mail : ihtifaz@uad.ac.id

Vol.1, No 1\&2, Juni-Desember 2018, pp. 69-88

ISSN p:2622-4755 e:2622-4798.

DOI: https://doi.org/10.12928/ijiefb.v1i1.287

\title{
Pengaruh Program Loyalitas terhadap Kesetiaan Konsumen pada Industri Halal di Yogyakarta
}

\section{Mufti Alam Adha ${ }^{1 *}$, Rofiul Wahyudi ${ }^{1}$, Faiza Husnayeni Nahar ${ }^{2}$}

${ }^{1}$ Universitas Ahmad Dahlan, Jl. Ringroad Selatan, Tamanan, Bantul, Daerah Istimewa Yogyakarta, Indonesia

2Universitas Muhammadiyah Yogyakarta, Jl. Ringroad Selatan, Tamantirto, Bantul, Daerah Istimewa Yogyakarta, Indonesia

*e-mail: mufti.alam@pbs.uad.ac.id 


\section{Pengaruh Program Loyalitas terhadap Kesetiaan Konsumen pada Industri Halal di Yogyakarta}

\author{
Mufti Alam Adha ${ }^{1 *}$, Rofiul Wahyudi ${ }^{1}$, Faiza Husnayeni Nahar ${ }^{2}$ \\ ${ }^{1}$ Universitas Ahmad Dahlan, Jl. Ringroad Selatan, Tamanan, Bantul, \\ Daerah Istimewa Yogyakarta, Indonesia \\ 2Universitas Muhammadiyah Yogyakarta, Jl. Ringroad Selatan, Tamantirto, \\ Bantul, Daerah Istimewa Yogyakarta, Indonesia \\ *e-mail: mufti.alam@pbs.uad.ac.id
}

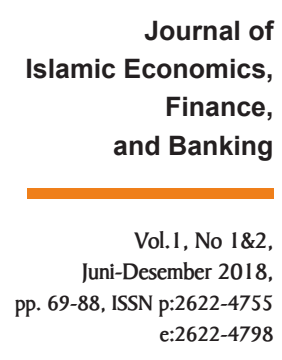

\begin{abstract}
This study aims to examine the effect of perceived benefits of loyalty programs, which include: financial benefits, social benefits, hedonic benefits, symbolic benefits of loyalty programs in the Halal Industry. This study also examined the effect of loyalty programs on brand loyalty. This research was conducted using a quantitative approach, namely by conducting surveys, online with a sample of 200 respondents. The data in this study were processed using the Structural Equation Modeling (SEM) analysis version 21. The results showed that the financial benefit variables, social benefts, symbolic benefits had a significant positive effect on loyalty programs. While the hedonic variable on loyalty programs shows a negative relationship. This study also confirms the significant positive effect of the loyalty program on brand loyalty.
\end{abstract}

\section{Keywords:}

Loyalty Program, Brand loyalty, Halal Industry

\begin{abstract}
Abstrak
Penelitian ini bertujuan untuk menguji pengaruh persepsi manfaat program loyalitas, yang meliputi: manfaat keuangan, manfaat sosial, manfaat hedonis, manfaat simbolis pada program loyalitas di Industri Halal. Penelitian ini juga menguji pengaruh program loyalitas pada kesetiaan merek. Penelitian ini dilakukan menggunakan pendekatan kuantitatif, yaitu dengan melakukan survei, melalui daring dengan jumlah sampel sebesar 200 responden. Data dalam penelitian ini diolah dengan menggunakan alat analisis Structural Equation Modeling (SEM) versi 21. Hasil penelitian menunjukkan bahwa variabel manfaat keuangan, manfaat sosial, manfaat simbolis berpengaruh
\end{abstract}


positif signifikan pada program loyalitas. Sedangkan variabel hedonic terhadap program loyalitas menunjukkan hubungan yang negatif. Penelitian ini juga mengkonfirmasi pengaruh positif signifikan program loyalitas pada kesetiaan merek.

\section{Kata Kunci:}

Program Loyalitas, Kesetiaan Merek, Industri Halal.

\section{PENDAHULUAN}

Pada era globalisasi ini perkembangan dalam dunia bisnis semakin hari semakin berkembang dan ketat. Banyak perusahaan yang kemudian tidak lagi memfokuskan aktivitas pemasaran mereka semata-mata pada pencarian pembeli baru, namun sudah lebih kepada usaha untuk mempertahankan dan meningkatkan kesetiaan pelanggan lama. Dalam terminologi pemasaran dapat dikatakan bahwa tujuan perusahaan terkait dengan pemasaran saat ini telah bergeser dari akuisisi pembeli (customer acquisition) kepada kesetiaan pelanggan (Dorotic et al., 2012).

Dalam hal ini maka, perusahaan semakin gencar menerapkan upaya-upaya untuk mendukung strategi perusahaan, mereka tidak hanya berfokus pada kualitas produk yang baik, akan tetapi perusahaan juga berusaha sedemikian rupa untuk mencoba memberikan pelayanan terbaik guna semakin mempererat hubungan dan memberikan nilai lebih serta kepuasan tersendiri bagi konsumen. Kepuasan pelanggan diperlukan bagi kesuksesan bisnis (Roehm et al., 2002). Namun kepuasan saja tidak cukup untuk membangun atau membentuk basis pelanggan yang loyal.

Potensi bisnis industri halal di dunia sangat besar. Saat ini berbagai negara, baik negara muslim maupun non-muslim berlomba-lomba menggarap potensi bisnis syariah. Berdasarkan laporan Global Islamic Report 2016-2017 nilai belanja makanan dan gaya hidup (food and lifestyle sector expenditure) Muslim di sektor halal dunia mencapai US\$ 1,9 triliun pada tahun 2015 dan diperkirakan akan naik menjadi US\$ 3 triliun pada tahun 2021 (Rasyid, 2017). Di Indonesia sendiri terdapat sepuluh sector dengan kontribusi yang paling besar yaitu, keuangan, makanan, wisata dan perjalanan, fashion, kosmetik, farmasi, media dan rekreasional, kebugaran, pendidikan dan seni budaya (Siregar, 2017).

Dapat dikatakan bahwa dengan semakin berkembangnya dunia industri sekarang ini, maka para pelaku usaha juga harus semakin jeli untuk melihat ruang dan celah yang dapat diolah sebagai suatu peluang untuk menciptakan kepuasan pelanggan. Sehingga dapat berakhir pada segala sesuatu yang menimbulkan sikap loyalitas pelanggan bagi kelangsungan suatu perusahaan. Perusahaan yang ingin mengembangkan keberadaan dan eksistensinya tentu memiliki strategi-strategi dalam usaha pemasaran. Setiap perusahaan yang ada menginginkan 
agar pelanggan mereka tetap setia, tidak berpindah, dan melakukan pembelian berulang pada produknya. Hal itu dapat terjadi pasti tidak terlepas dari relationship marketing yang merupakan strategi dari perusahaan untuk menarik minat dari pelanggan untuk datang ke tempat tersebut dan diharapkan dapat membuat pelanggan itu menjadi loyal (Suh dan Yi, 2012).

Relationship marketing merupakan proses pembentukan relasi dimana dalam proses tersebut menciptakan, memiliki, dan memberikan nilai tersendiri di mata konsumen dan pihak-pihak yang bersangkutan lainnya. Pi et al., (2010), menyatakan bahwa relationship marketing memungkinkan perusahaan untuk meningkatkan loyalitas pelanggan. Hu et al., (2010), juga menemukan bahwa hubungan yang baik memiliki pengaruh yang signifikan terhadap loyalitas pelanggan. Bahkan Pi et al., (2010), berpendapat bahwa relationship marketing memiliki aspek periklanan, promosi, positioning, public relation, dan direct marketing untuk menciptakan jalan yang lebih efektif dan efisien untuk berhubungan dengan konsumen.

Salah satu cara perusahaan untuk mempertahankan pelanggannya dengan menggunakan strategi relationship marketing, yaitu program loyalitas (program kesetiaan), dimana konsumen akan mendapat rewards (suatu bentuk penghargaan dari perusahaan) atas pembelian yang mereka lakukan, dalam bermacam-macam bentuk, biasanya berupa produk tambahan atau hadiah atau jasa lain, dan juga merupakan bentuk pernyataan perusahaan bahwa mereka adalah pelanggan yang berharga (Kim, Lee, Choi, Wu, dan Johson, 2013).

Berman dan Evans (2001) menyatakan bahwa program kesetiaan mempunyai fitur-fitur unik dari setiap retailer yang berbeda-beda dan tidak dapat ditukarkan di tempat lain. Ada suatu range rewards untuk menstimuli pembelian jangka pendek dan jangka panjang. Komunikasi dengan konsumen dilakukan secara personal. Pelanggan yang sering berbelanja dibuat merasa 'spesial' atau diperlakukukan lebih baik dibandingkan yang lain. Aturan-aturan untuk berpartisipasi dipublikasikan secara luas dan jarang berubah. Program-programnya dipromosikan dan didukung oleh adanya keanggotaan (membership).

Keberhasilan program ini didasarkan pada asumsi bahwa perilaku pembelian konsumen dapat dirubah dalam suatu tata cara yang menguntungkan bagi pemasar melalui pendekatan rasional, semakin banyak mereka berbelanja, semakin besar rewards yang akan didapatkan (Evanschitzky et al., 2012). Untuk dapat mebuat pelanggan berbelanja lebih banyak atau lebih sering, yang berarti mereka kembali lagi untuk melakukan pembelian ulang, retailer harus dapat memberikan kepuasan dan nilai tambah, karena program loyalitas yang baik memiliki tiga komponen yang saling melengkapi, yaitu: rewards (dapat berupa voucher, potongan harga, atau poin), value-added benefits (misalnya, special offer, newsletter, dan member events), dan customer recogni- 
tion (club database); memahami pelanggan melalui nama mereka dan mengetahui apa yang menjadi kebutuhan, keinginan serta perhatian

mereka (Wirtz et al., 2007).

Meskipun program loyalitas sudah populer dan banyak diterapkan oleh perusahaan, yang perlu diketahui dan dikaji lebih dalam bagaimana keefektifan program tersebut dan dampaknya pada perusahaan, terutama dalam hal keuntungan (Gandomi dan Zolfaghari, 2013) serta meningkatkan kesetiaan pelanggan (Hennig-Thurau dan Rudolph, 2009). Karena hanya akan sia-sia apabila program loyalitas tidak dapat meningkatkan kesetiaan pelanggan dan laba perusahaan. Pemasar harus jeli dan sensitif dalam melihat perilaku konsumen, terutama dalam menyikapi program loyalitas.

Penelitian sebelumnya, yang dilakukan oleh Kang et al., (2015) menguji program loyalitas hanya menggunakan persepsi manfaat secara financial dan manfaat social. Untuk penelitian selanjutnya Kang et al., (2015) menyarankan untuk menggunakan persepsi manfaat lainnya, seperti manfaat secara hedonis dan manfaat secara simbolis, yang mungkin saja memunculkan peran potensial lain dari program loyalitas. Oleh karena itu, penelitian ini mencoba untuk menjelaskan gap dari penelitian sebelumnya dengan menambahkan persepsi manfaat lainnya, yaitu manfaat hedonis dan manfaat simbolis.

Persepsi manfaat yang dirasakan oleh pelanggan dalam program loyalitas menjelaskan alasan pelanggan ikut serta dalam program loyalitas. Dan dari persepsi manfaat tersebut, timbul keinginan atau motivasi untuk ikut dalam program loyalitas yang ditawarkan oleh perusahaan dan menguatkan hubungan antara konsumen dan perusahaan (Bolton et al., 2004). Dengan demikian, jika pelanggan merasakan sedikit bahkan tidak ada manfaat dari keikutsertaan dalam loyalitas program yang perusahaan tawarkan, maka hal ini menjadi tidak efesien dan kerugian bagi perusahaan (De Wulf et al., 2001).

\section{Objective of the Study}

1. Mengidentifikasi hubungan manfaat financial berpengaruh positif terhadap program loyalitas.

2. Mengidentifikasi hubungan manfaat social berpengaruh positif terhadap program loyalitas.

3. Mengidentifikasi hubungan manfaat hedonic berpengaruh positif terhadap program loyalitas.

4. Mengidentifikasi hubungan manfaat symbolic berpengaruh positif terhadap program loyalitas.

5. Menangkap hubungan program loyalitas berpengaruh positif terhadap loyalitas konsumen pada perusahaan. 


\section{Research Question}

1. Apakah manfaat financial berpengaruh positif terhadap program loyalitas?

2. Apakah manfaat social berpengaruh positif terhadap program loyalitas?

3. Apakah manfaat hedonic berpengaruh positif terhadap program loyalitas?

4. Apakah manfaat symbolic berpengaruh positif terhadap program loyalitas?

5. Apakah program loyalitas berpengaruh positif terhadap loyalitas konsumen pada perusahaan?

\section{Research Significant}

Penelitian ini menguji dampak program loyalitas industri halal yang ada di Yogyakarta diantaranya Karita, Pands, dan Elita. Beberapa argumen yang diajukan memilih industri halal, mereka banyak menawarkan program loyalitas pada konsumen. Sebagai indikatornya banyaknya jumlah pelanggan dari industri halal menjadi anggota dan mengikuti program loyalitas.

\section{LITERATURE REVIEW}

\section{Relationship Marketing}

Perusahaan membutuhkan relationship yang baik dengan konsumen. Relationship marketing berarti terjadi perubahan dari sekedar berorientasi pada penjualan menjadi berorientasi pada pelanggan. Relationship marketing menitik beratkan kepada membangun dan mengembangkan hubungan dengan konsumen, Ini terkait dengan definisi marketing itu sendiri yaitu antara lain menciptakan, menjaga, dan meningkatkan hubungan dengan konsumen dan para stakeholder, dengan memberikan keuntungan kepada masing-masing pihak. Menurut Pi et al., 2010, relationship marketing adalah pengenalan setiap pelanggan secara lebih dekat dengan menciptakan komunikasi dua arah dengan mengelola suatu hubungan yang saling menguntungkan antara pelanggan dan perusahaan.

Hu et al., (2010), menyatakan bahwa untuk membangun dan mengembangkan relationship marketing maka perusahaan harus memperhatikan Mutual benefit (keuntungan bersama), commitment (kesetiaan atau kepastian), comunication (komunikasi atau hubungan), dan authencity (kebenaran). Sedangkan menurut McIlroy dan Barnett (2000), beberapa manfaat spesifik dari penggunaan relationship marketing antara lain adalah memperoleh profitabilitas dari pelanggan yang loyal, adanya peluang yang besar untuk menjual produk baru

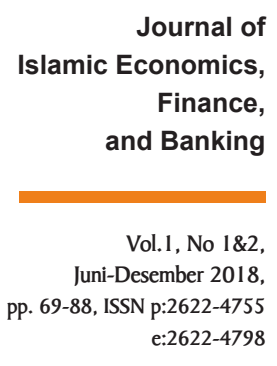


kepada pelanggan yang sudah loyal, memungkinkan promosi tanpa biaya (word of mouth), memperoleh informasi umpan balik dari pelanggan yang sudah loyal.

\section{Customer Retention}

Menjaga dan mengelola pelanggan dengan baik merupakan tujuan strategis untuk mengupayakan pemeliharaan hubungan jangka panjang dengan pelanggan (Kivetz dan Simonson, 2002). Program customer retention menjadi salah satu inti utama dari aktivitas relationship marketing. Paradigma dan cara berpikir perusahaan tidak lagi didominasi pada bagaimana cara mendapatkan pelanggan baru, tetapi lebih ke arah bagaimana mempertahankan pelanggan lama.

Menurut Kivetz dan Simonson (2002), proses menarik dan mempertahankan pelanggan memiliki beberapa tahapan. Tahap awal adalah suspects, seseorang atau perusahaan yang memiliki kecenderungan untuk membeli produk atau pelayanan. Tahap selanjutnya adalah mengidentifikasi suspects tersebut menjadi prospek dengan kemungkinan untuk membeli yang tinggi dan rendah. Tugas marketing disini adalah untuk menjadikan prospek-prospek yang sudah diidentifikasi menjadi pelanggan pertama kemudian pelanggan berulang dan pada tahap selanjutnya menjadikan sebagai klien. Yang dimaksud klien disini adalah pelanggan dengan perlakuan yang spesial dan berpengetahuan.

Program selanjutnya adalah mengubah klien menjadi member, dengan melalui program keanggotaan yang menawarkan keuntungankeuntungan bagi klien yang bersedia ikut dalam keanggotaan. Tahap setelah itu adalah mengubah klien menjadi advocates yaitu pelanggan yang secara antusias merekomendasikan perusahaan penjual produk serta jasa kepada prospek pelanggan yang lain. Level paling tinggi dari proses pengembangan pelanggan adalah menjadikan pelanggan sebagai partner. Pada tingkatan ini pelanggan memiliki kepuasan yang paling tinggi terhadap produk dan jasa yang dijual.

\section{Program Loyalitas}

Salah satu penerapan strategi mempertahakankan pelanggan (customer retention) adalah melalui program loyalitas (Kang et al., 2015). Berhubungan dengan hal tersebut, perusahaan dapat mendesain program loyalitas yang sesuai untuk pelanggannya. Program loyalitas ini akan sangat membantu perusahaan dalam mempertahankan pelanggan, meningkatkan kepuasan, dan menjaga agar pelanggan tidak tergiur oleh berbagai tawaran yang diberikan oleh kompetitor lain.

Program loyalitas menurut Palmatier (2007) adalah program yang ditawarkan kepada pelanggan untuk membangun ikatan emosional pelanggan terhadap sebuah merek. Dengan demikian dalam hal ini, 
program loyalitas bukan semata-mata bertujuan untuk meningkatkan pembelian ulang pelanggan. Program loyalitas bertujuan untuk membangun hubungan dengan pelanggan sehingga akan menjadikan pelanggan tersebut loyal di mana akan selalu melakukan pembelian atas produk dan jasa kepada perusahaan yang menerapkan program loyalitas tersebut.

Terdapat dua jenis program loyalitas, yaitu terbatas dan terbuka. Program loyalitas terbatas tidak dapat diikuti oleh setiap pelanggan karena untuk mengikuti program loyalitas ini maka pelanggan harus memenuhi prosedur yang diterapkan oleh perusahaan seperti membayar biaya kesertaan dan kadang-kadang terdapat kriteria tertentu yang harus dipenuhi seperti volume pembelian tertentu dan pendapatan minimum yang dimiliki pelanggan. Sementara itu, program loyalitas terbuka merupakan jenis program loyalitas yang dapat diikuti oleh setiap pelanggan tanpa ada persyaratan tertentu yang harus dipenuhi.

\section{Membangun program loyalitas}

Perusahaan menerapkan program loyalitas untuk mempengaruhi persepsi pelanggan dari status mereka, kebiasaan membeli dan hubungan pelanggan dengan perusahaan dengan demikian mendorong loyalitas pelanggan yang lebih besar (Henderson et al., 2011). Dengan demikian program loyalitas memiliki keuntungan finansial (Bolton et al., 2004), seperti diskon pelanggan khusus untuk anggota loyalitas program, menawarkan cash-back, dan kupon (Mimouni-Chaabane \& Volle, 2010). Pelanggan juga akan merasakan manfaat sosial, seperti pertemanan, persahabatan, dan pengakuan pribadi (aktualisasi diri) dari ikut berpartisipasi dalam loyalitas program (Gwinner et al., 1998).

Perasaan kekeluargaan yang diciptakan oleh program loyalitas pelanggan memberikan perasaan memiliki antara pelanggan dan perusahaan, perasaan penting dan terintegrasi ini merupakan sarana untuk memenuhi kebutuhan emosional (McMillan \& Chavis, 1986). Ikatan sosial ini sulit untuk dihilangkan dan kemungkinan pelanggan akan mempertahankan hubungan mereka dengan perusahaan. Selain itu, persepsi pelanggan terhadap nilai dapat meningkatkan loyalitas untuk perubahan hubungan (Sirdeshmukh et al., 2002;. Yi \& Jeon, 2003). Kegunaan yang dirasakan dari program loyalitas, baik secara finansial dan sosial, harus meningkatkan loyalitas pelanggan ke program (Meyer-Waarden, 2007). Oleh karena itu, hipotesis penelitian ini:

$\mathrm{H}_{1}$ : Manfaat financial yang ditawarkan oleh program loyalitas berpengaruh positif terhadap program loyalitas.

$\mathrm{H}_{2}$ : Manfaat social yang ditawarkan oleh program loyalitas berpengaruh positif terhadap program loyalitas. 


\section{Manfaat Hedonic}

Nilai hedonis berasal dari pengalaman pelanggan yang emosional IHTIFAZ - JIEFB dan dapat memebrikan kepuasan secara pribadi (Hirshman dan Holbrook, 1982) yang berhubungan dengan belanja, penggunaan media, dan peningkatan perilaku kesetiaan (Arnold dan Reynolds, 2003; Babin dan Attaway 2000; Babin et al., 1994; Jones et al., 2006). Manfaat hedonis mungkin relevan untuk program loyalitas melalui dua dimensi: eksplorasi dan hiburan. Mencoba produk-produk baru yang inovatif, memuaskan rasa ingin tahu tentang penawaran promosi atau produk baru, atau mencari informasi untuk mengikuti trend baru merupakan contoh dari perilaku eksplorasi (Arnold dan Reynolds, 2003; Baumgartner dan Steenkamp, 1996).

Loyalitas program juga memungkinkan pelanggan untuk menikmati pengalaman unik, karena banyak organisasi menawarkan kesenangan dengan memberikan insentif, seperti mendapatkan hadiah jalan-jalan ke luar negeri selama beberapa hari atau menghadiri festival yang menarik. Selain itu, karena kegiatan tersebut dapat secara intrinsik menarik minat konsumen untuk mengikuti program loyalitas (Hirshman dan Holbrook, 1982), program loyalitas dapat memberikan perasaan senang dan sukacita pada pelanggan. Johnson (1999) berpendapat bahwa program loyalitas dapat menarik konsumen karena kesenangan yang terkait dengan pengumpulan poin yang dapat ditukarkan dengan hadiah. Oleh karena itu penulis membuat hipotesis:

$\mathrm{H}_{3}$ : Manfaat hedonic yang ditawarkan oleh program loyalitas berpengaruh positif terhadap program loyalitas.

\section{Manfaat Symbolic}

Manfaat simbolik merupakan manfaat ekstrinsik yang dapat dirasakan oleh pelanggan, bahwa produk atau jasa dapat memberikan kebutuhan untuk mengekspresikan diri, menunjukkan status konsumen dan pengakuan secara sosial (Keller, 1993). Karena perusahaan membangun pengetahuan pelanggan, melalui penawaran program loyalitas sebagai kesempatan untuk membedakan atau mendapat perlakuan khusus antara pelanggan yang menganggap penyesuaian penawaran merupakan tanda penghormatan atau kekhususan (Gordon et al., 1998). Akibatnya konsumen merasakan manfaat pengakuan yang perusahaan berikan (Csikszentmmihalyi, 2000); pelanggan merasa karyawan perusahaan dan manajer memperlakukan mereka lebih baik daripada perusahaan memperlakukan pelanggan lain yang bukan anggota dari program loyalitas (Beatty et a.I, 1996;. Gwinner et al., 1998).

Program loyalitas selanlanjutnya berfokus tidak hanya pada produk tetapi juga pengalaman kepemilikan dan konsumsi yang dirasakan pelanggan (McAlexander et al., 2002). Akibatnya, program loyalitas 
dapat meningkatkan persepsi manfaat secara social bagi masyarakat (Libermann, 1999), sehingga anggota menganggap mereka bagian dari sebuah kelompok eksklusif atau pelanggan yang diperlakukan istimewa, teridentifikasi dengan adanya grup tersebut, serta dapat berbagi nilai yang terkait dengan merek (Muniz dan O'Guinn, 2001). Oleh karena itu penulis membuat hipotesis:

$\mathrm{H}_{4}$ : Manfaat symbolic yang ditawarkan oleh program loyalitas berpengaruh positif terhadap program loyalitas.

\section{Membangun loyalitas pada perusahaan}

Dengan bergabungnya konsumen ke dalam program loyalitas, pelanggan menjadi bagian dari kelompok yang bisa dikatakan pelanggan eksklusif dengan perlakuan yang istimewa dari perusahaan (Muniz \& O'Guinn, 2001). Pelanggan yang loyal terhadap program loyalitas cenderung akan menguatkan ikatan dengan perusahaan tersebut (Ahearne et al., 2005). Karena interaksi yang sering dilakukan dapat meningkatkan persepsi pelanggan menjadi "orang dalam (insider)" dan dapat menghidupkan kembali identitas sosial mereka (Bhattacharya et al., 1995).

Penelitian sebelumnya menunjukkan bahwa partisipasi yang lebih besar menyebabkan pelanggan lebih setia kepada program dan perusahaan (misalnya, Bolton et al., 2000; Dowling \& Uncles, 1997). Dalam hal ini, program loyalitas merupakan tahap dalam proses dimana pelanggan mengembangkan loyalitasnya pada perusahaan (Kimcet al., 2013). Pelanggan yang mengembangkan loyalitasnya pada perusahaan umumnya tertarik dengan program loyalitas dan manfaat dari program loyalitas (Hu et al., 2010). Yi dan Jeon (2003) menegaskan bahwa kesetiaan pada perusahaan yang merupakan hasil dari loyalitas program, merupakan pelanggan dalam kondisi keterlibatan yang tinggi. Hubungan positif antara program loyalitas dan loyalitas pada perusahaan konsisten (Suh \& Yi, 2012). Oleh karena itu penulis membuat hipotesis:

$\mathrm{H}_{5}$ : Program loyalitas berpengaruh positif terhadap loyalitas pelanggan pada perusahaan.

Kerangka model yang diajukan penelitian ini:

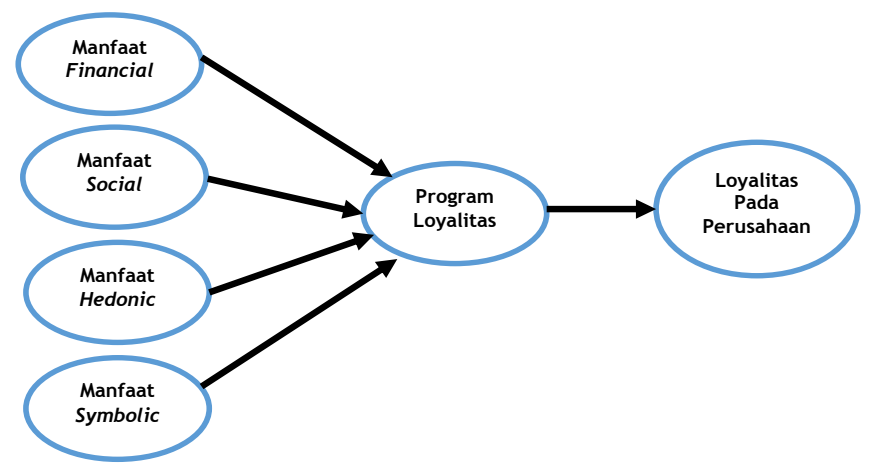




\section{METODOLOGI}

IHTIFAZ - JIEFB

\section{Desain Penelitian}

Penelitian ini menggunakan metode penelitian kuantitatif. Penelitian kuantitatif adalah penelitian yang mencoba untuk melakukan pengukuran yang akurat terhadap sesuatu (Cooper dan Schindler, 2011). Pengujian variabel penelitian disebut juga sebagai ilmu yang sebenarnya dengan menggunakan cara-cara matematika dan statistik untuk mengukur variabel penelitian tersebut dengan objektivitas yang tinggi. Penelitian ini mencoba untuk menguji teori (theory testing) melalu uji hipotesis dengan tujuan untuk membuktikan apakah hipotesis terdukung atau tidak terdukung.

\section{Populasi dan Sampel}

Penentuan sampel dilakukan dengan metode non-probability sampling, yaitu purposive sampling. Purposive sampling adalah suatu sampel yang ditarik dari elemen individu didasarkan pada pertimbangan pribadi dengan cara menentukan kriteria responden terlebih dahulu. Ide dasar dari pengambilan sampel adalah bahwa dengan menyeleksi bagian dari elemen-elemen populasi, kesimpulan tentang keseluruhan populasi dapat diperoleh (Cooper dan Schindler, 2011). Karakteristik responden penelitian ini dilihat dari variabel demografi, yang terdiri dari: jenis kelamin, umur, tingkat pendidikan, jenis pekerjaan dan tingkat pengeluaran. Unit analisis penelitian ini adalah individu. Jumlah sampel penelitian ini adalah 200 pelanggan yang mengikuti program loyalitas industri halal yang ditawarkan oleh Karita, Pands, dan Elita.

\section{Metoda Pengumpulan Data Penelitian}

Jenis data dalam penelitian ini adalah data primer, yaitu data yang diperoleh secara langsung dari responden (pelanggan). Jenis data yang digunakan adalah data cross-section, yaitu studi dengan mengumpulkan data dalam satu titik waktu (Cooper dan Schindler, 2011). Peneliti menggunakan metoda survei sebagai teknik pengumpulan data. Cooper dan Schindler (2011) menyebutkan ada beberapa cara yang dapat dilakukan melalui metoda survei yaitu: self-administered survey, interview melalui telepon, dan interview secara personal.

Pada penelitian ini data yang digunakan adalah data primer, yaitu data yang diperoleh dari survei yang meliputi penyebaran kuesioner kepada responden yang bersangkutan. Sebelum melakukan survei kepada responden penelitian, terlebih dahulu dilakukan pre-test pada instrumen pengukuran untuk mememnuhi uji validitas konten. Untuk mengukur item-item pertanyaan peneliti menggunakan Skala Likert 5 Poin, dari 1 mewakili "sangat tidak setuju" sampai 5 "sangat setuju". 


\section{Variabel, Konstruk dan Pengukuran}

Dalam penelitian ini penulis menggunakan sekumpulan item pengukuran yang terdiri dari 26 item pernyataan. Seluruh instrumen dalam penelitian ini merupakan instrumen yang di adapatasi dari penelitian terdahulu. Dalam penelitian ini ada tiga konstruk pengukuran yang utama, yaitu persepsi manfaat yang dirasakan pelanggan (financial benefits, social beneffts, hedonic benefits, symbolic benefits), loyalty program dan company loyalty.

\section{Teknik Analisis Data}

Pengujian hipotesis model penelitian ini menggunakan Structural Equation Modeling (SEM). Gudono (2014) menjelaskan bahwa SEM dapat digunakan untuk mengolah data variabel yang dapat diukur (measured variabels) ataupun yang tidak dapat diukur (construct atau latent variables). Lebih lanjut terdapat beberapa alasan yang mendasari peneliti menggunakan SEM, yaitu: terdapat hubungan antarvariabel yang kompleks, ada variabel yang unobservable atau merupakan konsep (variabel laten), peneliti ingin menguji model ftness secara keseluruhan (Gudono, 2014).

Peneliti menggunakan two step approach dalam penerapan SEM yaitu: (1) peneliti melakukan analisis pada model pengukuran (measurement model) yang berisi langkah-langkah untuk menghubungkan variabel terukur (observed variabels) dengan variabel laten atau dengan kata lain memastikan seluruh item loading sesuai dengan variabel latennya dan (2) melakukan analisis pada model struktural (structural models) yang berisi langkah-langkah untuk menguji hubungan variabel laten yang satu dengan variabel laten lainnya secara keseluruhan (Gudono, 2014). Software yang digunakan peneliti adalah IBM SPSS AMOS 21, keunggulan software ini dapat digunakan untuk menguji fit model dan lebih jauh mengevaluasi validitas dan reliabilitas konstruk penelitian.

\section{DATA, ANALYSIS AND DISCUSSION}

Tiga jenis data disajikan dan dianalisis, mereka (a) latar belakang responden, atau mereka yang telah mengisi kuesioner, (b) data yang berkaitan dengan aspek keuangan. Semua data dianalisis menggunakan sederhana dan metode deskriptif statistik. Setelah diverifikasi, 200 sampel yang valid untuk lebih lanjut diproses.

\section{Karakteristik Demografi Responden}

Karakteristik demografi responden penelitian ini dilihat dari variabel demografi, yang terdiri dari: Jenis kelamin, umur, tingkat pendidikan, jenis pekerjaan dan tingkat pengeluaran.

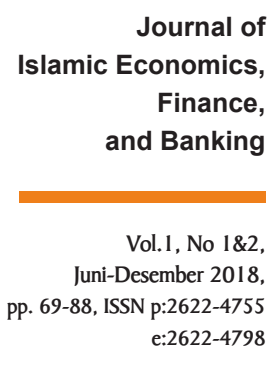

conomics,

Vol.1, No 1\&2,

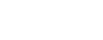




\section{Jenis Kelamin}

Table 1. Jenis Kelamin Responden

\begin{tabular}{rlrrrr}
\hline & & Frequency & Percent & Valid Percent & $\begin{array}{c}\text { Cumulative } \\
\text { Percent }\end{array}$ \\
\hline \multirow{3}{*}{ Valid } & Laki-laki & 52 & 26.0 & 26.0 & 26.0 \\
& Perempuan & 148 & 74.0 & 74.0 & 100.0 \\
& Total & 200 & 100.0 & 100.0 & \\
\hline
\end{tabular}

Sumber: Data Diolah (2018)

Tabel 1 jenis kelamin responden jelas menunjukkan bahwa sebagian besar responden berjenis kelamin perempuan sebanyak (74\%) dan laki-laki berjumlah (26\%).

2. Umur Responden

Table 2 umur responden di bawah ini menunjukkan distribusi responden berdasarkan umur, sebagai berikut:

Table 2. Umur Responden

\begin{tabular}{|c|c|c|c|c|c|}
\hline & & Frequency & Percent & Valid Percent & $\begin{array}{l}\text { Cumulative } \\
\text { Percent }\end{array}$ \\
\hline \multirow{9}{*}{ Valid } & $>51$ tahun & 5 & 2.5 & 2.5 & 2.5 \\
\hline & $15-20$ tahun & 17 & 8.5 & 8.5 & 11.0 \\
\hline & $21-25$ tahun & 38 & 19.0 & 19.0 & 30.0 \\
\hline & 26-30 tahun & 36 & 18.0 & 18.0 & 48.0 \\
\hline & 31-35 tahun & 60 & 30.0 & 30.0 & 78.0 \\
\hline & $36-40$ tahun & 24 & 12.0 & 12.0 & 90.0 \\
\hline & 41-45 tahun & 12 & 6.0 & 6.0 & 96.0 \\
\hline & 46-50 tahun & 8 & 4.0 & 4.0 & 100.0 \\
\hline & Total & 200 & 100.0 & 100.0 & \\
\hline
\end{tabular}

Sumber: Data Diolah (2018)

Seperti yang bisa dilihat, $30 \%$ atau sebagian besar berada di antara 31-35 tahun, 19\% berusia antara 21-25 tahun. Namun, bila ditinjau distribusinya dibagi secara wajar atau biasa. 
3. Tingkat Pendidikan Responden

Tabel 3. Tingkat Pendidikan Responden

\begin{tabular}{llrrrr}
\hline & & Frequency & Percent & Valid Percent & Cumulative Percent \\
\hline Valid & Diploma & 24 & 12.0 & 12.0 & 12.0 \\
& Magister & 37 & 18.5 & 18.5 & 30.5 \\
& Sarjana & 99 & 49.5 & 49.5 & 80.0 \\
SMA & 34 & 17.0 & 17.0 & 97.0 \\
& SMP & 6 & 3.0 & 3.0 & 100.0 \\
Total & 200 & 100.0 & 100.0 & \\
\hline
\end{tabular}

Sumber: Data Diolah (2018)

Akhirnya, kebanyakan dari mereka adalah 49.5\% lulusan S1, 18,5\% adalah lulusan gelar Master, 17\% Sekolah Menengah Atas, 3\% adalah lulusan SMP.

4. Jenis Pekerjaan Responden

Tabel 4. Jenis Pekerjaan Responden

\begin{tabular}{llrrrr}
\hline & Frequency & Percent & Valid Percent & $\begin{array}{c}\text { Cumulative } \\
\text { Percent }\end{array}$ \\
\hline \multirow{4}{*}{ Mahasiswa } & 32 & 16.0 & 16.0 & 16.0 \\
Manajer & 36 & 18.0 & 18.0 & 34.0 \\
& Pelajar & 6 & 3.0 & 3.0 & 37.0 \\
& Profesi lainnya & 5 & 2.5 & 2.5 & 39.5 \\
& Profesional & 41 & 20.5 & 20.5 & 60.0 \\
& Staf & 29 & 14.5 & 14.5 & 74.5 \\
& Teknisi & 21 & 10.5 & 10.5 & 85.0 \\
& Wiraswasta & 30 & 15.0 & 15.0 & 100.0 \\
& Total & 200 & 100.0 & 100.0 & \\
\hline
\end{tabular}

Sumber: Data Diolah (2018)

Tabel 4 jenis pekerjaan responden di atas menunjukkan bawah sebagian besar jenis pekerjaan responden profesional $20.5 \%$ diikuti Manager sebesar $18 \%$, Mahasiswa $16 \%$, wiraswasta $15 \%$, staff $14.5 \%$, teknisi $10.5 \%$. Jenis pekerjaan responden berikutnya Pelajar $3 \%$ dan profesi lainnya sebesar $2.5 \%$.

5. Tingkat Pengeluaran Responden

Ihtifaz: Journal of Islamic Economics, Finance, and Banking 
Tabel 5. Tingkat Pengeluaran Responden

\begin{tabular}{llrrrr}
\hline & Frequency & Percent & Valid Percent & $\begin{array}{c}\text { Cumulative } \\
\text { Percent }\end{array}$ \\
\hline Valid & $>3.000 .000$ & 32 & 16.0 & 16.0 & 16.0 \\
& $1.000 .000-1.500 .000$ & 51 & 25.5 & 25.5 & 41.5 \\
& $1.500 .001-2000.000$ & 69 & 34.5 & 34.5 & 76.0 \\
$2.000 .001-3000.000$ & 42 & 21.0 & 21.0 & 97.0 \\
$700.001-1.000 .000$ & 6 & 3.0 & 3.0 & 100.0 \\
Total & 200 & 100.0 & 100.0 & \\
\hline
\end{tabular}

Sumber: Data Diolah (2018)

Tabel 5 tingkat pengeluaran responden menunjukkan bahwa tingkat pengeluaran responden sebagian besar pada level 1.500.001-2.000.000 $(34.5 \%)$, pengeluaran responden antara $1.000 .000-1.500 .000$ (25.5\%). Sedangkan pengeluaran responden antara 2.000.001 3.000 .000 sebesar (21\%) dan paling rendah sebesar 3\%.

\section{HASIL dan PEMBAHASAN}

\section{Hasil Uji Model Pengukuran}

Hasil terakhir model pengukuran dapat digambarkan berikut di bawah ini:

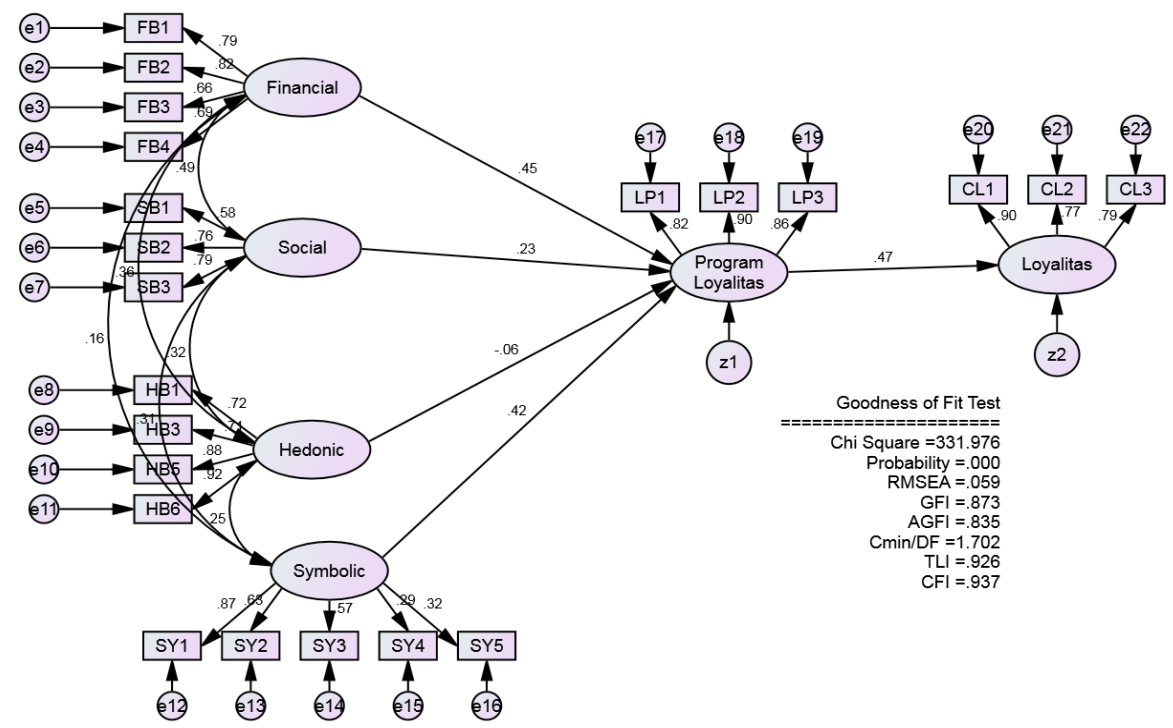

Gambar 1. Hasil Uji Model

Berdasarkan hasil uji kesesuain model, kriteria yang disyaratkan dalam uji Goodness of Fit Model menunjukkan lima diantaranya pada kondisi good fit, sedangkan tiga diantaranya pada posisi marginal-fit. Namun demikian, secara keseluruhan dapat dikatakan bahwa kesesuaian model memiliki tingkat Goodness of Fit Model yang baik. 
Mengacu hasil uji dapat dijelaskan bahwa nilai chi square sebesar 331,976 , nilai probabilitas model sebesar 0,000 , CMIN/DF sebesar 1,702 lebih kecil dari 2,00. Nilai GFI sebasar 08,73 mendekati 1, nilai AGFI sebesar 0,835 masih mendekati 1, nilai RMSEA sebesar 0,059 masih lebih kecil dari 0,08, nilai TLI sebesar 0,926 masih lebih besar dari standar cut off value. Berikut ringkasan hasil uji model:

Tabel 6. Hasil Uji Goodness of Fit Model

\begin{tabular}{llcc}
\hline \multicolumn{1}{c}{ Indeks } & \multicolumn{1}{c}{ Cut off value } & Hasil & Keterangan \\
\hline Chi Square & $\geq 0.05$ & 331,976 & Marginal-fit \\
Probability & $\geq 0.05$ & 0,000 & Marginal-fit \\
CMIN/DF & $<2$ (Byrne, 1998) & 1,702 & Good Fit \\
GFI & $\geq 0.90$ & 0,873 & Marginal-fit \\
AGFI & $\geq 0.80$ & 0,835 & Good Fit \\
RMSEA & $<0,08$ (Browne dan Curdeck, 1993) & 0,059 & Good Fit \\
TLI & $>0.90$ (Arbuckle, 1997) & 0,926 & Good Fit \\
CFI & $>0.90$ & 0,937 & Good Fit \\
\hline
\end{tabular}

Sumber : Hasil Analisis Data Primer dengan AMOS 21 (2018)

\section{Hasil Uji Hipotesis}

Hasil perhitungan data dengan bantuan software Smart PLS 2.0 menunjukkan sebagai berikut:

Tabel 7. Hasil Regression Weights

\begin{tabular}{lllrrrrr}
\hline & & & Estimate & S.E. & C.R. & P & Label \\
\hline Program_Loyalitas & $<---$ & Financial & .622 & .117 & 5.298 & $* * *$ \\
Program_Loyalitas & $<---$ & Social & .266 & .095 & 2.790 & .005 \\
Program_Loyalitas & $<---$ & Hedonic & -.061 & .064 & -.956 & .339 \\
Program_Loyalitas & $<---$ & Symbolic & 1.237 & .345 & 3.581 & $* * *$ \\
Loyalitas & $<---$ & $\begin{array}{l}\text { Program_- } \\
\text { Loyalitas }\end{array}$ & .511 & .084 & 6.107 & $* * *$ \\
\hline
\end{tabular}

Sumber: Data diolah dengan AMOS 21 (2018)

Tabel 7 hasil regression weights di atas memberikan jawaban hipotesis penelitian sebagai berikut:

Variabel Manfaat financial berpengaruh signifikan terhadap program loyalitas konsumen yang ditunjukkan dengan nilai $\mathrm{P}$ di bawah taraf signifikansi $5 \%$ atau 0,05 yaitu 0,000 dengan standar kebiasaan nilai CR yang digunakan adalah sebesar 2,00 . Nilai CR pada variabel manfaat financial dengan program loyalitas sebesar 5,298 yang berarti nilai CR lebih besar dari 2. Hasil uji ini menunjukkan bahwa koefisien jalur adalah signifikan. Nilai estimate antara variabel manfaat financial dengan program loyalitas sebesar 0,622 yang berarti apabila program loyalitas 
mengalami peningkatan sebesar 1 , maka manfaat financial juga akan mengalami peningkatan sebesar 0,622.

Variabel manfaat social berpengaruh signifikan terhadap program loyalitas yang ditunjukkan dengan nilai $\mathrm{P}$ di bawah taraf signifikansi $5 \%$ atau 0,05 yaitu 0,005 dengan standar kebiasaan nilai CR yang digunakan adalah sebesar 2,00. Nilai CR pada variabel manfaat social dengan program loyalitas sebesar 2,790 yang berarti nilai CR lebih besar dari 2. Hasil uji ini menunjukkan bahwa koefisien jalur adalah signifikan. Nilai estimate antara variabel manfaat social dengan program loyalitas sebesar 0,266 yang berarti apabila program loyalitas mengalami peningkatan sebesar 1 , maka manfaat social juga akan mengalami peningkatan sebesar 0,266.

Variabel manfaat symbolic berpengaruh signifikan terhadap program loyalitas yang ditunjukkan dengan nilai $P$ di bawah taraf signifikansi $5 \%$ atau 0,05 yaitu 0,000 dengan standar kebiasaan nilai CR yang digunakan adalah sebesar 2,00 . Nilai CR pada variabel manfaat symbolic dengan program loyalitas sebesar 3,581 yang berarti nilai CR lebih besar dari 2. Hasil uji ini menunjukkan bahwa koefisien jalur adalah signifikan. Nilai estimate antara variabel manfaat symbolic dengan program loyalitas sebesar 1,237 yang berarti apabila program loyalitas mengalami peningkatan sebesar 1 , maka manfaat symbolic juga akan mengalami peningkatan sebesar 1.237.

Variabel hedonic terhadap program loyalitas menunjukkan negatif yang ditunjukkan dengan nilai P di atas taraf signifikansi 5\% atau 0,05 yaitu 0,339 dengan standar kebiasaan nilai CR yang digunakan adalah sebesar 2,00. Nilai CR pada variabel manfaat hedonic dengan program loyalitas sebesar -0.956 yang berarti nilai CR lebih besar dari 2 . Hasil uji ini menunjukkan bahwa koefisien jalur adalah tidak signifikan. Nilai estimate antara variabel manfaat hedonic dengan program loyalitas sebesar -0,061 berarti apabila program loyalitas mengalami peningkatan sebesar 1, maka manfaat hedonic juga akan mengalami peningkatan sebesar $-0,061$.

Hasil uji menunjukkan bahwa variabel program loyalitas berpengaruh positif terhadap loyalitas konsumen pada perusahaan yang ditunjukkan oleh nilai $P$ di bawah taraf signifikansi $5 \%$ atau 0,05 yaitu 0,000 dengan standar kebiasaan nilai CR yang digunakan adalah sebesar 2,00. Nilai CR pada variabel manfaat loyalitas dengan program loyalitas sebesar 6,107 yang berarti nilai CR lebih besar dari 2. Hasil uji ini menunjukkan bahwa koefisien jalur adalah signifikan. Nilai estimate antara variabel loyalitas dengan program loyalitas sebesar 0.511 yang berarti apabila program loyalitas mengalami peningkatan sebesar 1 , maka loyalitas juga akan mengalami peningkatan sebesar 0.511.

Hasil uji variabel financial, social, dan symbolic mendukung temuan penelitian (Sirdeshmukh et al., 2002;. Yi \& Jeon, 2003), (Meyer-Waarden, 2007) dan (Libermann, 1999 dan Csikszentmmihalyi, 2000). Sedangkan variabel hedonic tidak berpengaruh terhadap program loyalitas konsumen ini bertolak belakang dengan Johnson (1999). 
Hasil penelitian menunjukkan bahwa:

1. Variabel manfaat financial berpengaruh signifikan terhadap program loyalitas konsumen.

2. Variabel Manfaat social berpengaruh signifikan terhadap program loyalitas

3. Variabel manfaat symbolic berpengaruh signifikan terhadap program loyalitas

4. Variabel hedonic terhadap program loyalitas menunjukkan hubungan yang negatif

5. Variabel program loyalitas berpengaruh positif terhadap loyalitas konsumen

6. Sampel yang diteliti juga harus ditambahkan, karena masih banyak halal industri dibidang fashion.

\section{REFERENSI}

Arnold, M. J, Reynolds, K. E. (2003). Hedonic shopping motivation. Journal of Retailing, 79 (2) : 77-95.

Babin, B J, Darden W, Griffin M. (1994). Work and/or fun: measuring hedonic and utilitarian shopping value. Journal of Consumer Research, 20 (4): 644-57.

Babin, B. J, and Attaway, J. S. (2000). Atmospheric affect as a tool for creating value and gaining share of customer. Journal of Business Research, 49 (2): 91-9

Backhaus, C. (2012). Consequences of customer loyalty to the loyalty program and to the company. Journal of the Academy of Marketing Science, 40(5), 625-638.

Baumgartner, H and Steenkamp, J. B. (1996). Exploratory consumer buying behavior: conceptualization and measurement. International of Journal Reserach Marketing, 13 (2): 121-37.

Beatty, S.E, Mayer M, Coleman, J.E, Reynolds, K.E, Lee J. (1996). Customer-sales associate retail relationships. Journal of Retail ;72 (3): $223-47$.

Berman, B. (2006). Developing an effective customer loyalty program. California Management Review, 49(1), 123-148.

Bhattacharya, C. B., \& Sen, S. (2003). Consumer-company identification: A framework for understanding consumers' relationships with companies. Journal of Marketing, 67(2), 76-88.

Bhattacharya, C. B., Rao, H., \& Glynn, M.A. (1995). Understanding the bond of identification: An investigation of its correlates among art museum. Journal of Marketing, 59(4), 46-57. 
Bolton, R. N., Lemon, K. N., \& Verhoef, P. C. (2004). The theoretical underpinnings of customer asset management: A framework and propositions for future research. Journal of the Academy of Marketing Science, 32(3), 271-292.

Chaudhuri, A., \& Holbrook, M. B. (2001). The chain of effects from brand trust and brand affect to brand performance: The role of brand loyalty. Journal of Marketing, 65(2), 81-93.

Csikszentmmihalyi, M. (2000). The costs and benefits of consuming. Journal of Consumer Research; 27 (2): 267-72.

Dorotic, M., Bijmolt, T. H. A.,\&Verhoef, P.C. (2012). Loyalty programs: Current knowledge and research directions. International Journal of Management Reviews, 14(3), 217-237.

Edwards, M. R. (2005). Organizational identification: A conceptual and operational review. International Journal of Management Reviews, 7(4), 207-230.

Evanschitzky, H., Ramaseshan, B., Woisetschlager, D.M., Richelsen, V., Blut, M., \& Backhaus, C. (2012). Consequences of customer loyalty to the loyalty program and to the company. Journal of the Academy of Marketing Science, 40(5), 625-638.

Gandomi, A., \& Zolfaghari, S. (2013). Profitability of loyalty reward programs: An analytical investigation. Omega, 41(4), 797-807.

Gordon, M.E, McKeage K, Fox, M.A. (1998). Relationship marketing effectiveness: the role of involvement. Journal of Psychology Marketing ;55(5):443-59.

Gudono. 2014. Analisis Data Multivariat. Edisi 4. BPFE. Yogyakarta. Gwinner, K. P., Gremler, D.D., \& Bitner, M. J. (1998). Relational benefits in services industries: The customer's perspective. Journal of the Academy of Marketing Science, 26(2), 101-114.

Hair, J. F., W. C. Black., B. J. Babin., dan R. E Anderson. (2010). Multivariate Data Analysis: A Global Prespective. Seventh Edition. Pearson Education, Inc. United States of America.

Henderson, C. M., Beck, J. T., \& Palmatier, R. W. (2011). Review of the theoretical underpinnings of loyalty programs. Journal of Constructivist Psychology, 21(3), 256-276.

Hirshman, E, Holbrook M. (1982). Hedonic consumption: emerging concepts methods and propositions. Journal of Marketing, 46(3):92102.

Homburg, C., Wieseke, J., \& Hoyer, W. D. (2009). Social identity and the service-profit chain. Journal of Marketing, 73(2), 38-54.

Hsiu-Yuan Hu, Ching-Chan Cheng, Shao-I Chiu and Fu-Yuan Hong, (2010), "A study of customer satisfaction, customer loyalty and 
quality attributes in Taiwan's medical service industry", African Journal of Business Management Vol. 5(1), pp. 187-195.

Hu, H., Huang, C., \& Chen, P. (2010). Do reward programs truly build loyalty for lodging industry? International Journal of Hospitality Management, 29(1), 128-135.

Hughes, D. E., \& Ahearne, M. (2010). Energizing the reseller's sales force: The power of brand identification. Journal of Marketing, 74(4), 81-96.

Johnson, K. (1999). Making loyalty program more rewarding. Journal of Direct Marketing 1999; 61(11): 24-7.

Kang, Jun, Alejandro, Thomas. B, and Groza, Mark. D. (2015). Customercompany identification and the effectiveness of loyalty programs. Journal of Business Research, 68, 464-471.

Keller, L.K. Conceptualizing, measuring and managing customer-based brand equity. Journal of Marketing, 1993; 57 (1): 1-22.

Kim, H., Lee, J. Y., Choi, D., Wu, J., \& Johnson, K. K. P. (2013). Perceived benefits of retail loyalty programs: Their effects on program loyalty and customer loyalty. Journal of Relationship Marketing, 12(2), 95-113.

Kivetz, R., \& Simonson, I. (2002). Earning the right to indulge: Effort as a determinant of customer preferences toward frequency program rewards. Journal of Marketing Research, 39(2), 155-170.

Kotler, P., \& Armstrong, G. (2004). Principles of marketing, (10. th ed), New Jersey: Prentice Hall.

Lee, E. M., Park, S., Rapert, M. I., \& Newman, C. L. (2011). Does perceived consumer fit matter in corporate social responsibility issues? Journal of Business Research, 65(11), 1558-1564.

Lee, K. S., \& Tan, S. J. (2003). E-retailing versus physical retailing: A theoretical model and empirical test of consumer choice. Journal of Business Research, 56(11), 877-885.

Leenheer, J., van Heerde, H. J., Bijmolt, T. H. A., \& Smidts, A. (2007). Do loyalty programs really enhance behavioral loyalty? An empirical analysis accounting for selfselecting members. International Journal of Research in Marketing, 24(1), 31-47.

Libermann, Y. (1999) Membership club as a tool for enhancing buyers' patronage. Journal of Business Research ;45(3): 291-7.

Mc Alexander, J. H, Schouten, J.W, Koenig, H.F. (2002) Building brand community. Journal of Marketing ; 66 (1):38-54.

McIlroy, A., \& Barnettm S. (2000), "Building customer relationships: Do discount cards work? Managing Service Quality, Vol. 10 (6), pp. 347-370. 
Mimouni-Chaabane, A., \& Volle, P. (2010). Perceived benefits of loyalty programs: Scale development and implications for relational

\section{IHTIFAZ - JIEFB}
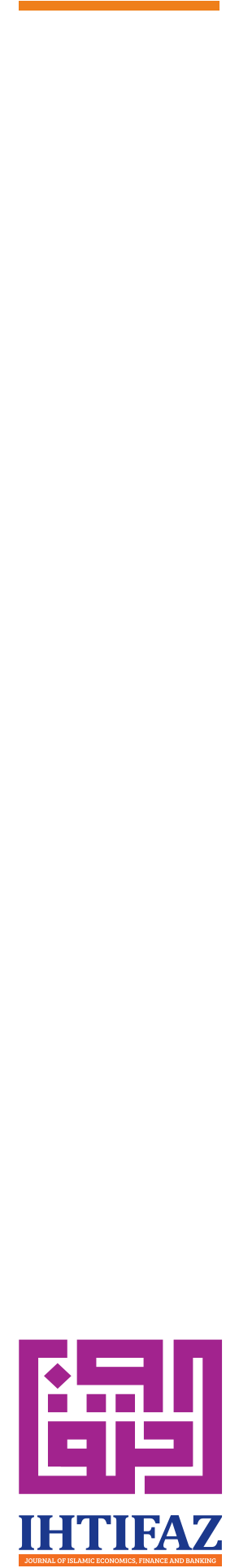

UNIVERSITAS AHMAD DAHLAN

Kampus 4 Ringrod Selatad Tahlan

Banguntapan, Bantu

Yogyakarta 55191 Yogyakarta 55191
Muniz, A. M, O'Guinn, T. C.(2001). Brand community. Journal of Consumer Research; 27 (4): 412-32.Palmatier, R. W., Dant, R. P., Grewal, D., \& Evans, K. R. (2006). Factors influencing the effectiveness of relationship marketing: A meta-analysis. Journal of Marketing, 70(4), 136-153.

Palmatier, R. W., Gopalakrishna, S., \& Houston, M. B. (2006). Returns on business-to business relationship marketing investments: Strategies for leveraging profits.

Palmatier, R.W., Scheer, L. K., \& Steenkamp, J. B. E.M. (2007). Customer loyalty to whom? Managing the benefits and risks of salespersonowned loyalty. Journal of Marketing Research, 44(2), 185-199.

Pi, W.P., and Huang, H.Hong, (2010), "Effects of Promotion on Relationship Quality and Customer Loyalty in The Airline Industry: The Relationship Marketing Approach", African Journal of Business Management Vol.5 (11), pp.4403-4414.

Reinartz, W., \& Kumar, V. (2002). The mismanagement of customer loyalty. Harvard Business Review, 80(7), 86-95.

Roehm, M. L., Pullins, E. B., \& Roehm, H. A., Jr. (2002). Designing loyalty-building programs for packaged goods brands. Journal of Marketing Research, 39(2), 202-213.

Suh, J., \& Yi, Y. (2012). Do consumption goals matter? The effects of online loyalty programs in the satisfaction-loyalty relation. Psychology and Marketing, 29(8), 549-557.

Uncles, M.D., Dowling, G. R., \& Hammond, K. (2003). Customer loyalty and customer loyalty programs. Journal of Consumer Marketing, 20(4), 294-316.

Wagner, T., Hennig-Thurau, T., \& Rudolph, T. (2009). Does customer demotion jeopardize loyalty? Journal of Marketing, 73(3), 69-85.

Yi, Y., \& Jeon, H. (2003). Effects of loyalty programs on value perception, program loyalty, and brand loyalty. Journal of the Academy of Marketing Science, 31(3), 229-240. 